Advances in Cement Research Volume 28 Issue 9

Performance of white Portland cement matrixes blended with nanosilica and limestone for architectural applications Tobón, Mendoza Reales and Payá Bernabeu
Advances in Cement Research, 2016, 28(9), 606-615

http://dx.doi.org/10.1680/jadcr.16.00015

Paper 1600015

Received 08/02/2016; revised 23/06/2016; accepted 06/07/2016

Published online ahead of print 27/07/2016

Keywords: admixtures/blended cements/hydration/lime/

mineralogy

\title{
Performance of white Portland cement matrixes blended with nanosilica and limestone for architectural applications
}

\section{Jorge I. Tobón}

Grupo del Cemento y Materiales de Construcción (CEMATCO), Universidad Nacional de Colombia, Medellín, Colombia (corresponding author: jitobon@unal.edu.co)

\section{Oscar A. Mendoza Reales}

Núcelo de Materiaís e Tecnologías Sustentáveis (NUMATS),

Universidade Federal do Rio de Janeiro, Rio de Janeiro, Brazil

\section{Jordi Payá Bernabeu}

Instituto de Ciencia y Tecnología del Hormigón (ICITECH), Universitat Politècnica de València, Valencia, Spain

This research evaluates the combination of nanosilica particles and ground limestone as mineral additions for white Portland cement (WPC) matrixes, envisioning architectural applications where the whiteness of the final product is a key feature. The WPC pastes and mortars were fabricated with additions of nanosilica and substitutions of cement by limestone. An experimental campaign was carried out to study the effect of the combination of nanoparticles and mineral additions over the hydration process, whiteness and mechanical performance of the WPC matrices. It was found that nanosilica in combination with limestone is an excellent option as a mineral addition for WPC, since it can improve its properties in the fresh and hardened states without altering the colour of the final product.

\section{Introduction}

White Portland cement (WPC) is a key element in architectural and decorative concrete applications due to its mechanical strength and colour (Veiga and Gastaldini, 2012). WPC is characterised for having a high development of early strength, which allows a more efficient use of the formwork, and increasing the speed of the construction process (Lübeck et al., 2012). Its white colour not only confers aesthetic advantages, but also makes spaces look more luminous and causes the architectural finishing to stand out (Badogiannis et al., 2005). Exterior white surfaces, such as roofing and facades, also offer a high albedo effect, reducing the cooling needs inside the building by reflecting some of the solar radiation, thereby increasing the energy efficiency of buildings (Pisello, 2015).

Usually, WPC has a higher content of tricalcium aluminate $\left(\mathrm{C}_{3} \mathrm{~A}\right)$ in comparison with ordinary Portland cement (OPC), and almost null contents of chromophoric elements such as iron, manganese, chrome, titanium and vanadium (Hamad, 1995). WPC also has lower particle size and higher specific surface area, which causes a higher heat release and shorter setting time (Lübeck et al., 2012). High-purity kaolin, limestone and gypsum are required to produce WPC (Badogiannis et al., 2005); in addition, the cooling of the white clinker has to be done faster to avoid oxidation of metallic elements such as iron, chrome and titanium, which might be present in the clinkers at trace amounts (Hamad, 1995).
White Portland cement is produced at a higher temperature than OPC, which gives it a higher energy consumption and higher release of carbon dioxide $\left(\mathrm{CO}_{2}\right)$ (Hewlett, 2004), so the use of mineral admixtures in WPC is a research topic of great importance. Mineral additions to be blended with WPC must be white, which makes them more expensive, owing to the high purity required. Among the mineral additions that have been used in combination with WPC are limestone (Colak, 2008), metakaolin (Love et al., 2007; Siddique and Klaus, 2009; Talero, 2005), fly ash (Girão et al., 2010), rice husk ash (Ferraro and Nanni, 2012) and blast furnace slag (Dellinghausen et al., 2012). Limestone does not have pozzolanic activity (Colak, 2008); metakaolin usually presents yellow or pink tones that go against the aesthetic quality of the final product (Siddique and Klaus, 2009); fly ash is usually dark in colour, depending on its chemical composition (Zaeni et al., 2010); and rice husk ash could contain carbon particles, which modifies the colour of the cement.

Nanosilica, which is most commonly produced by way of sol-gel techniques from silicate solutions or silane reagents (Jal et al., 2004), is white when it is in the agglomerated state. Nanosilica has significant positive effects in the properties of nanosilica-blended OPC (Tobón et al., 2012, 2015), and it is expected to reach an equally positive performance in WPC. Owing to its pozzolanic activity and its particle size, the nanosilica reacts with the calcium hydroxide $\left(\mathrm{Ca}(\mathrm{OH})_{2}\right)$ to form 


\section{Offprint provided courtesy of www.icevirtuallibrary.com Author copy for personal use, not for distribution}

additional calcium silicate hydrate $(\mathrm{C}-\mathrm{S}-\mathrm{H})$ (Björnström et al., 2004), improving the properties of the mix in both the fresh and hardened states (Berra et al., 2012). Additionally, owing to its size and chemical affinity, the nanosilica refines the pore structure of the matrix and increases its mechanical strength and durability ( $\mathrm{Ji}, 2005)$.

Few studies have been performed using WPC and nanosilica (Sáez del Bosque et al., 2013). It has been found that the high surface area of nanosilica particles is capable of modifying not only the kinetics of the formation of $\mathrm{C}-\mathrm{S}-\mathrm{H}$ and calcium hydroxide, but also the kinetics of formation of ettringite (Aft) and calcium monosulfoaluminate (AFm); this is probably due to an adsorption of ions in the surface of the nanoparticles that is able to modify the sulfate equilibrium in the solution (Land and Stephan, 2012). It has also been found that nanosilica can increase the length of the $\mathrm{C}-\mathrm{S}-\mathrm{H}$ chains from WPC hydration and stabilises AFt up to $28 \mathrm{~d}$ of hydration (Sáez del Bosque et al., 2013).

Limestone, which is white when it is free of chromophoric elements, is used as a filler to substitute clinker, decreasing costs and modifying some properties of the mix in the fresh and hardened states (Courard et al., 2011). It has been found that limestone blended in Portland cement is capable of improving the durability of the cementing matrix (Colak, 2008), and that the mechanical and durability properties of the cementing matrix are highly dependent on the water-to-cement ratio (Palm et al., 2016).

Knowing that limestone is white when it has high purity, and nanosilica is usually in the form of white powder, or clear to white aqueous dispersions, it is interesting to study their combination as a blend for WPC. The main goal is to take advantage of the pozzolanic properties of the nanosilica, and use limestone as the filler. This approach will increase the total volume of mixture produced, and decrease the amount of cement consumed. This work assesses the combination of nanosilica and limestone as a mineral admixture for WPC to increase the mechanical strength of WPC matrixes without modifying the colour, envisioning architectural applications where the whiteness of the final product is a key feature.

\section{Experimental programme}

Materials and sample preparation

The materials used were: WPC (produced by Cementos Argos SA from Colombia); nanosilica Meyco MS 685 (denoted NS in the experimental mixture nomenclature) suspended in water with a solids concentration of $25 \%$ (produced by BASF Chemicals); superplasticiser Pozzolith 460N (denoted SP) (produced by BASF Chemicals); natural limestone ground and passed through a no. 200 sieve (denoted L); and ASTM C778 (ASTM, 2013) standard 20-30 sand (passing the $850 \mu \mathrm{m}$ sieve and retained in the $600 \mu \mathrm{m}$ sieve). A summary of the physical

\begin{tabular}{lll}
\hline Parameter & WPC & Nanosilica \\
\hline Density: $\mathrm{g} / \mathrm{cm}^{3}$ & $3 \cdot 15$ & $1 \cdot 12$ \\
$\mathrm{pH}$ & $\mathrm{NA}$ & $10 \pm 1$ \\
Solids concentration: \% & NA & $40 \pm 1$ \\
Surface area & $541^{\mathrm{a}}$ & $284 \cdot 85^{\mathrm{b}}$
\end{tabular}

Note: NA, not applicable.

ablaine surface area $\left(\mathrm{m}^{2} / \mathrm{kg}\right)$.

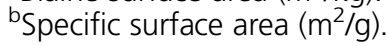

Table 1. Physical properties of the materials according to manufacturer

properties of the materials is presented in Table 1. The chemical composition of the raw materials was obtained by X-ray fluorescence using ARL $8680 \mathrm{~s}$ equipment in boron lithium oxide pills $\left(\mathrm{B}_{4} \mathrm{Li}_{2} \mathrm{O}_{7}\right)$. WPC pastes and mortars with different additions of nanosilica by mass of cement and substitutions of limestone also by mass of cement were fabricated. A summary of the different percentages of additions and substitutions and the nomenclature used for the samples is presented in Table 2.

Pastes were prepared with a constant water-to-solids ratio of $0 \cdot 50$. First a WPC and limestone blend was produced by dry mixing using a rotating mill, then the nanosilica aqueous dispersions were combined with the mixing water and mechanically mixed for $2 \mathrm{~min}$, and finally the two previous components were combined and hand mixed until a homogeneous paste was obtained. Samples were stored in $50 \mathrm{ml}$ plastic airtight containers at room temperature and, when they had reached testing age, were ground in a grinding mill using acetone as refrigerant media. The excess acetone was removed using a vacuum pump and afterwards the samples were dried at $60^{\circ} \mathrm{C}$ until constant mass was reached, when they were sieved through a no. 200 sieve. An additional set of pastes was moulded in a coin-like form, with $1 \mathrm{~cm}$ dia. and $3 \mathrm{~mm}$ thick, to evaluate their colour. After curing for $3 \mathrm{~d}$ covered with a wet cloth in a sealed contained, at room temperature, the coin-shaped samples were demoulded, and their hydration was stopped using acetone and a convection oven set to $60^{\circ} \mathrm{C}$ for $24 \mathrm{~h}$.

Mortars with a water-to-cement ratio of 0.55 were prepared, following a procedure similar to the pastes; first a WPC and limestone blend was produced, then the nanosilica dispersions and the mixing water were combined, and finally the mortar was produced following the procedure presented in the ASTM C109/109 M (ASTM, 2016) standard. The flow of each mortar was measured following the ASTM 1437 (ASTM, 2015a) standard, and SP was added until a $105 \pm 5 \%$ flow was obtained. Mortars were moulded in $4.0 \times 4.0 \times 16 \mathrm{~cm}$ bars, three for each sample, and cured in a high-humidity environment for $24 \mathrm{~h}$; then demoulded and cured in calcium hydroxide saturated water until testing age. 


\begin{tabular}{|c|c|c|c|c|}
\hline Nomenclature & Nanosilica addition: wt\% & Limestone substitution: wt\% & WaterMPC & Water/solids \\
\hline WPC & - & - & 0.50 & \\
\hline $5 \% \mathrm{NS}$ & $5 \cdot 0$ & - & 0.53 & \\
\hline $10 \%$ NS & $10 \cdot 0$ & - & 0.55 & \\
\hline $5 \% N S+10 \% L$ & $5 \cdot 0$ & $10 \cdot 0$ & 0.58 & $0 \cdot 50$ \\
\hline $5 \% N S+20 \% L$ & $5 \cdot 0$ & $20 \cdot 0$ & 0.66 & \\
\hline $10 \% N S+10 \% L$ & $10 \cdot 0$ & $10 \cdot 0$ & 0.61 & \\
\hline $10 \% N S+20 \% L$ & $10 \cdot 0$ & $20 \cdot 0$ & 0.69 & \\
\hline
\end{tabular}

Table 2. Nomenclature and proportioning of samples

\section{Tests on cement pastes}

Pastes were used to study the influence of the nanosilica and the limestone on the mineralogy, kinetics of hydration and colour of the WPC matrices. Isothermal calorimetry tests were carried out to identify modifications in the kinetics of hydration during the first $40 \mathrm{~h}$ of hydration. X-ray diffraction (XRD) and thermogravimetric analysis (TGA) tests were carried out to identify any modifications of the type and amount of hydration products generated during the first $28 \mathrm{~d}$ of hydration. Whiteness index (WI) was measured to verify whether the nanosilica and the limestone had any affect over the colour of the WPC after $3 \mathrm{~d}$ of hydration.

Qualitative XRD data were collected using an XRD PANalytical X'Pert Pro MPD with a copper $(\mathrm{Cu})$ X-ray source $\left(\lambda_{\alpha 1}=0.154059 \mathrm{~nm}\right)$, in a $2 \theta$ interval between $6^{\circ}$ and $70^{\circ}$, with a step of $0.02^{\circ}$ and an accumulation time of $30 \mathrm{~s}$. XRD analysis carried out using High Score plus software. Quantitative XRD data were collected using the same equipment, in a $2 \theta$ interval between $6^{\circ}$ and $70^{\circ}$, with a step of $0.013^{\circ}$ and an accumulation time of $59 \mathrm{~s}$. TGA was carried out using a Netzsch Hi-Res TGA 2950 thermogravimetric analyser; the sample $(40 \pm 2 \mathrm{mg})$ was placed into an alumina crucible, using a nitrogen $\left(\mathrm{N}_{2}\right)$ atmosphere and a heating rate of $10^{\circ} \mathrm{C} / \mathrm{min}$ up to $700^{\circ} \mathrm{C}$. The WI was measured following the procedure of the ASTM E 313 (ASTM, 2015b) standard, using a BWTEK Glacier X spectrophotometer equipped with an Ocean Optics visible light source and $200 \mu \mathrm{m}$ T200 visible to near-infrared (VIS-NIR) optical fibres. Isothermal calorimetry was performed using a Tam Air isothermal calorimeter set to $25^{\circ} \mathrm{C}$; an admix device was used to mix the samples inside the calorimeter and avoid any data loss at the beginning of the reaction.

\section{Tests on cement mortars}

Mortars were used to study the influence of the nanosilica and the limestone on the mechanical properties of the WPC matrices. Mortar bars were cured for 1, 3, 7 and $28 \mathrm{~d}$, then their compressive strengths were measured following the ASTM C348 (ASTM, 2014a) and ASTM C349 (ASTM, 2014b) standards.

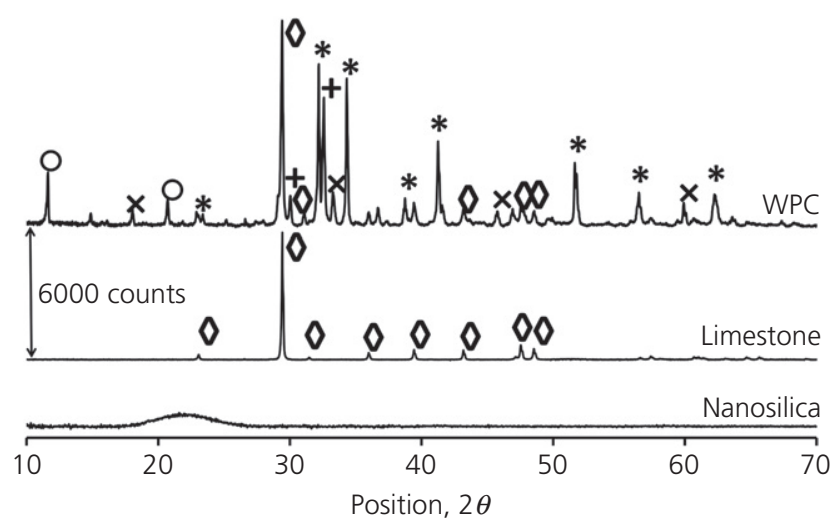

Figure 1. XRD patterns of WPC, limestone and nanosilica (*: alite; +: belite; $\times$ : celite; $\diamond$ : calcium carbonate; o: gypsum)

\section{Results and discussion}

Materials characterisation

The XRD patterns obtained for the limestone, WPC and nanosilica are presented in Figure 1. The limestone presented slender peaks characteristic of calcium carbonate $\left(\mathrm{CaCO}_{3}\right)$, without any detectable crystalline impurity. WPC presented the typical peaks associated with the anhydrous phases of cement, and also peaks associated with calcium carbonate. This indicates that during the production of WPC some percentage of carbonate was used as filler. Rietveld analysis was carried out to quantify the amount of calcium carbonate present in the WPC. The refinement was done using full proof. Results of this analysis are presented in Table 3. It was found that WPC contained $14.60 \%$ of calcium carbonate in its composition. Nanosilica was found to be of amorphous character.

The chemical composition of limestone, nanosilica and WPC are presented in Table 4. For limestone it was found that $55.37 \%$ of the sample corresponds to calcium oxide $(\mathrm{CaO})$, and $43 \cdot 04 \%$ corresponds to loss on ignition (LOI), associated with calcium carbonate decarbonation, which took place in the LOI test. Additionally, traces of metallic oxides were found in less than $1 \%$ of the total composition. These results indicate 


\section{Offprint provided courtesy of www.icevirtuallibrary.com}

Author copy for personal use, not for distribution

\begin{tabular}{lc}
\hline Component & Percentage: \% \\
\hline Alite $\left(\mathrm{C}_{3} \mathrm{~S}\right)$ & 59.60 \\
Belite $\left(\mathrm{C}_{2} \mathrm{~S}\right)$ & 9.28 \\
Celite $\left(\mathrm{C}_{3} \mathrm{~A}\right)$ & $5 \cdot 27$ \\
Gypsum & 11.63 \\
Calcium carbonate $\left(\mathrm{CaCO}_{3}\right)$ & 14.60 \\
& \\
Table 3. Rietveld quantification results for WPC (wRp: $0.0224 ;$ \\
$\left.\chi^{2}: 7.98\right)$
\end{tabular}

\begin{tabular}{lccc}
\hline Compound & $\begin{array}{c}\text { Limestone: } \\
\%\end{array}$ & $\begin{array}{c}\text { WPC: } \\
\%\end{array}$ & $\begin{array}{c}\text { Nanosilica: } \\
\%\end{array}$ \\
\hline Silica $\left(\mathrm{SiO}_{2}\right)$ & - & 18.57 & 93.56 \\
Aluminium oxide $\left(\mathrm{Al}_{2} \mathrm{O}_{3}\right)$ & 0.03 & 3.28 & 0.00 \\
Iron (III) oxide $\left(\mathrm{Fe}_{2} \mathrm{O}_{3}\right)$ & 0.02 & 0.34 & 0.39 \\
Calcium oxide $(\mathrm{CaO})$ & 55.37 & 65.02 & 0.22 \\
Magnesium oxide $(\mathrm{MgO})$ & 0.27 & 0.49 & 0.13 \\
Sodium oxide $\left(\mathrm{Na}_{2} \mathrm{O}\right)$ & - & 0.09 & 0.62 \\
Potassium oxide $\left(\mathrm{K}_{2} \mathrm{O}\right)$ & 0.02 & 0.02 & 0.02 \\
Sulfur trioxide $\left(\mathrm{SO}_{3}\right)$ & 0.24 & 3.46 & 0.30 \\
Chromium (III) oxide $\left(\mathrm{Cr}_{2} \mathrm{O}_{3}\right)$ & - & - & 0.04 \\
Manganese oxide $(\mathrm{MnO})$ & - & 0.01 & 0.01 \\
Phosphorus pentoxide $\left(\mathrm{P}_{2} \mathrm{O}_{5}\right)$ & 0.13 & 0.08 & 0.13 \\
Titanium dioxide $\left(\mathrm{TiO}_{2}\right)$ & - & 0.09 & 0.02 \\
Loss on ignition & 43.04 & 8.49 & 4.46
\end{tabular}

Table 4. X-ray fluorescence of limestone, WPC and nanosilica

that the limestone used was from a high-purity rock. WPC presented a high value of LOI associated with the decarbonation of the calcium carbonate present in its composition. Nanosilica was found to be mainly silicon dioxide $\left(\mathrm{SiO}_{2}\right)$. A more detailed characterisation of the particle size of the nanosilica has been reported previously (Mendoza et al., 2014).

\section{Results on WPC pastes}

\section{X-ray diffraction of WPC/nanosilica/limestone pastes}

The XRD patterns obtained for WPC pastes blended with nanosilica and limestone, after 1 and $28 \mathrm{~d}$ of curing, are presented in Figures 2 and 3, respectively. Similar results were found for samples cured for 3 and $7 \mathrm{~d}$ but they are not presented here. In all samples non-hydrated material was found, alite and belite after $1 \mathrm{~d}$ of hydration and mostly belite after $28 \mathrm{~d}$ of hydration; calcium carbonate was also found, as a result of the limestone in the original cement and the limestone replacement. The main hydration products found were calcium silicate hydrates $(\mathrm{C}-\mathrm{S}-\mathrm{H})$, calcium hydroxide and ettringite $(\mathrm{AFt})$. The presence of AFt and the absence of gypsum even from the first day of hydration indicate that all of the gypsum

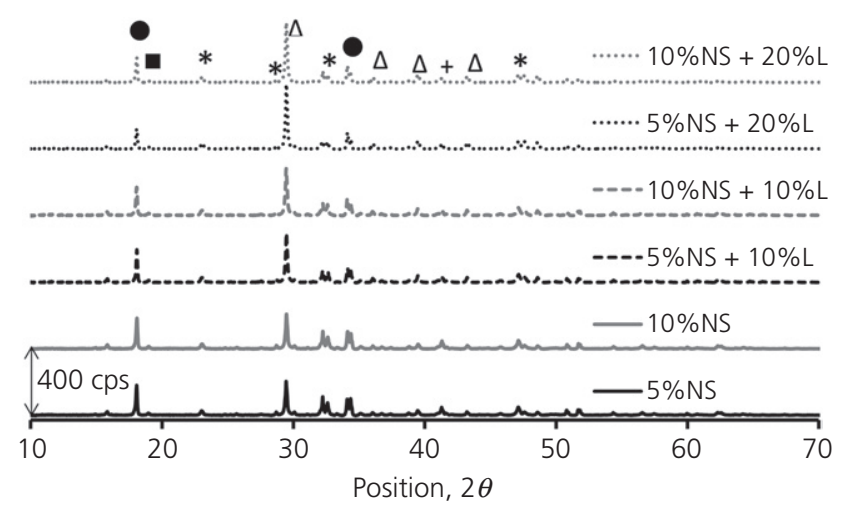

Figure 2. XRD patterns obtained after $1 d$ of hydration of samples of WPC blended with nanosilica and limestone (*: alite; + : belite; $\diamond$ : calcium carbonate; $\mathbf{\square}$ : AFt; $\bullet$ : calcium hydroxide; $\Delta$ : tobermorite/C-S-H; cps: counts per second)

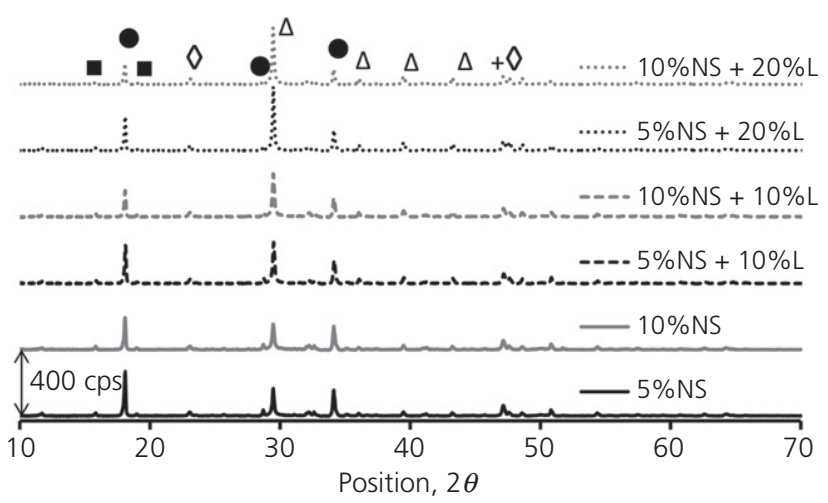

Figure 3. XRD patterns obtained after $28 \mathrm{~d}$ of hydration of samples of WPC blended with nanosilica and limestone (+: belite, $\diamond$ : calcium carbonate, $\mathbf{\square}$ : AFt, $\bullet$ : calcium hydroxide, $\Delta$ : tobermorite/C-S-H, cps: counts per second)

reacted with the tricalcium aluminate $\left(\mathrm{C}_{3} \mathrm{~A}\right)$ to form $\mathrm{AFt}$. There exists the possibility that the remaining $\mathrm{C}_{3} \mathrm{~A}$ could react later with the AFt to form AFm, but this was not detected.

The $\mathrm{C}-\mathrm{S}-\mathrm{H}$ was detected as a broad band between $29^{\circ}$ and $30^{\circ} 2 \theta$ and widened peaks associated with a tobermorite-like structure; this was attributable to its short-range crystalline structure (Chen et al., 2004). Calcium hydroxide was detected as sharp, high-intensity peaks, even at $1 \mathrm{~d}$ of hydration, attributable to the accelerating effect that the nanosilica has over the hydration reaction (Tobón et al., 2012). This behaviour indicates that the amounts of nanosilica used are not capable of combining all of the calcium hydroxide produced by the hydration reaction. The peaks of the same hydration products of different samples cannot be compared directly owing to the dilution effect of the real amount of cement in the sample, due to the limestone substitution. A detail of the main diffraction 


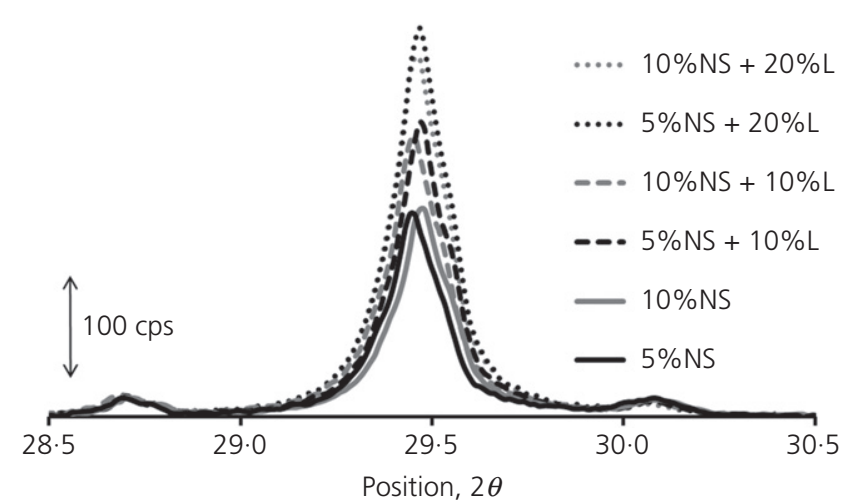

Figure 4. Detail of the main calcium carbonate diffraction peak obtained in the samples after $1 \mathrm{~d}$ of hydration

peak of calcium carbonate is presented in Figure 4. Calcium carbonate was found even in the samples blended only with nanosilica; this is attributable to the fact that the WPC already contained limestone as filler (supplementary mineral addition). Nevertheless, it can be seen that the intensity of the carbonate peak increases proportionally to the amount of limestone blended into the sample. Similar results were found after $28 \mathrm{~d}$ of hydration.

\section{Thermogravimetric analysis of WPC/nanosilica/ limestone pastes}

Up to $700^{\circ} \mathrm{C}$, two decomposition events were identified using the first derivate of the TGA curves. The first event, with a maximum around $105^{\circ} \mathrm{C}$ and going up to $220^{\circ} \mathrm{C}$, was associated with the combined dehydration of $\mathrm{C}-\mathrm{S}-\mathrm{H}$, calcium aluminate hydrates $(\mathrm{C}-\mathrm{A}-\mathrm{H})$, calcium silicoaluminate hydrates (C-A-S-H) and AFt (Sáez del Bosque et al., 2013); and the second, with a maximum around $430^{\circ} \mathrm{C}$, was associated with the dehydroxylation of calcium hydroxide (Ramachandran et al., 2002). All mass losses are associated with decomposition of hydration products formed during the hydration reaction of the cement.

Owing to the combination of different dehydration reactions in the first decomposition event, the mass loss with a DTG peak at around $105^{\circ} \mathrm{C}$ (measured from $60^{\circ} \mathrm{C}$ to $220^{\circ} \mathrm{C}$ ) was interpreted as directly indicative of a more or less advanced hydration process. The results obtained are presented in Figure 5. It was found that the $5 \% \mathrm{NS}$ and $10 \% \mathrm{NS}$ pastes showed the highest mass loss for the studied period (0-28 d). More hydrates were found in the $10 \% \mathrm{NS}$ paste than in the $5 \% \mathrm{NS}$ one, suggesting that there is an important contribution of nanosilica to the development of hydrates, probably due to a more extensive pozzolanic reaction: the more reactive silica there is, the more hydrates are formed. It was also found that the replacement of part of the WPC by limestone produced a decrease of mass loss in pastes in the peak with a maximum at $105^{\circ} \mathrm{C}$, and that the pozzolanic activity of nanosilica was not able to

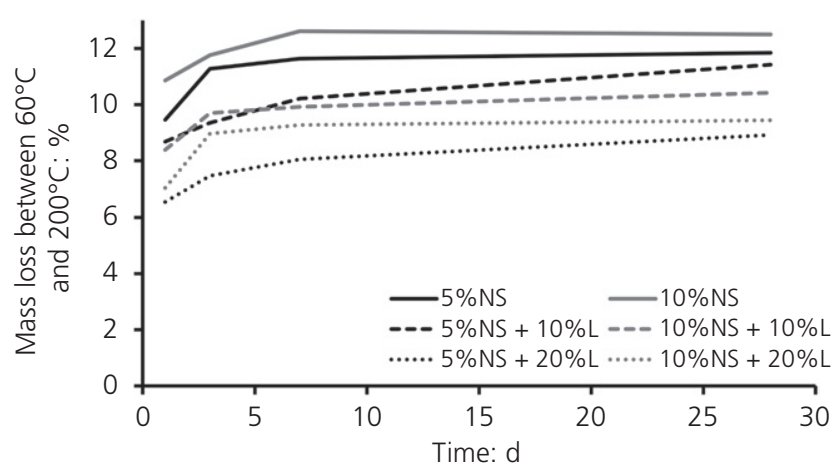

Figure 5. Mass loss associated with the first thermal event centred between $60^{\circ} \mathrm{C}$ and $220^{\circ} \mathrm{C}$ (decomposition of $\mathrm{C}-\mathrm{S}-\mathrm{H}+\mathrm{C}-\mathrm{A}-\mathrm{H}+\mathrm{C}-\mathrm{A}-\mathrm{S}-\mathrm{H}+\mathrm{AFt}$ ) in pastes of WPC blended with nanosilica and limestone

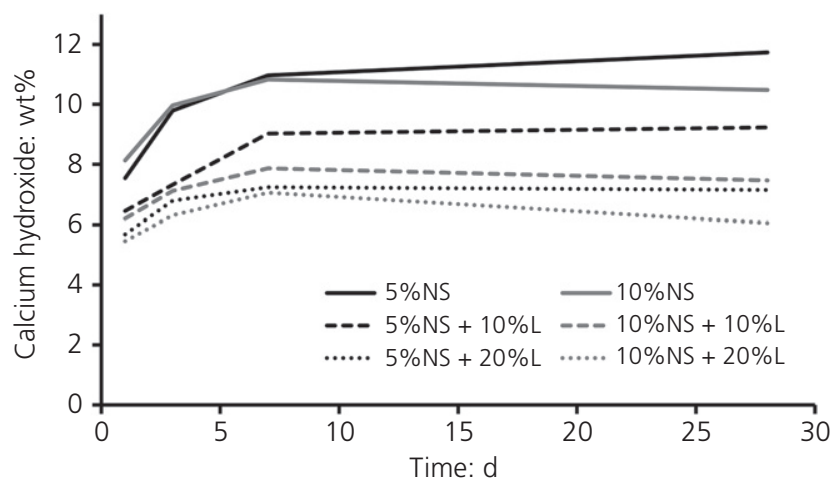

Figure 6. Calcium hydroxide content (mass fraction) in pastes of WPC blended with nanosilica and limestone

compensate for the decrease in hydration products caused by the dilution effect of limestone.

The mass loss corresponding to the second decomposition event was used to calculate the amount of calcium hydroxide present in each sample using Equation 1 (Mendoza and Tobón, 2013). Results are presented in Figure 6

$$
\text { 1. } \mathrm{Ca}(\mathrm{OH})_{2}=\left(H / \mathrm{MW}_{\mathrm{H}_{2} \mathrm{O}}\right) \times \mathrm{MW}_{\mathrm{Ca}(\mathrm{OH})_{2}}
$$

where $H$ is the mass loss due to dehydroxylation found in the TGA; $\mathrm{MW}_{\mathrm{H}_{2} \mathrm{O}}$ is the molecular weight of water; and $\mathrm{MW}_{\mathrm{Ca}(\mathrm{OH})_{2}}$ is the molecular weight of calcium hydroxide.

Samples blended with $10 \% \mathrm{~L}$ presented a higher content of calcium hydroxide than samples blended with $20 \% \mathrm{~L}$. This is attributed to the dilution effect of the substitution of WPC by limestone. Additionally, in the samples blended with $10 \% \mathrm{NS}$, the amount of calcium hydroxide was lower than the amount present in the samples blended with $5 \% \mathrm{NS}$ from the seventh 


\section{Offprint provided courtesy of www.icevirtuallibrary.com Author copy for personal use, not for distribution}

day onwards. This is due to a higher addition of nanosilica that combined a higher amount of calcium hydroxide to produce $\mathrm{C}-\mathrm{S}-\mathrm{H}$. From the first to the seventh day of hydration, both $5 \% \mathrm{NS}$ and $10 \% \mathrm{NS}$ samples show similar amounts of calcium hydroxide. It should be noticed that nanosilica not only has a chemical effect through pozzolanic reaction, but also a physical effect through nucleation, which accelerates the hydration of the cement owing to its high surface area (Tobón et al., 2012). Thus, more nanosilica will mean not only a higher and more rapid formation of $\mathrm{C}-\mathrm{S}-\mathrm{H}$ through pozzolanic reaction, but also a more rapid formation of calcium hydroxide due to nucleation, mostly at early ages (Abd El Aleem et al., 2014).

\section{Whiteness index of WPC/nanosilica/limestone pastes}

The coin-shaped pastes were used to measure the colour coordinates $L^{*}, a^{*}$ and $b^{*}$ at three points for all samples. The whiteness index (WI) was calculated using Equation 2, as indicated by the ASTM E 313 (ASTM, 2015b) standard. Results are presented in Figure 7.

2. $\mathrm{WI}=L^{*}-3 b^{*}+3 a^{*}$

The $L^{*}$ coordinate increased both with the addition of nanosilica and substitution of limestone, showing that the luminosity was increased in all cases. The $a^{*}$ and $b^{*}$ coordinates presented slight deviations to the green and yellow, but these deviations are characteristic of the cement and were not significantly altered either by the nanosilica or by the limestone. Despite some variations in WI between the control sample and the samples blended with nanosilica and limestone, the standard deviation bars indicate that there is not a significant difference in whiteness among them. This suggests that the nanosilica and the high-purity limestone do not modify the whiteness of the WPC matrix and are adequate additions for applications where the whiteness is a sensitive characteristic of the material.

\section{Isothermal calorimetry of WPC/nanosilica/ limestone pastes}

The results obtained for the first heat release peak, associated with the dissolution of the anhydrous phase and early age $\mathrm{AFt}$ formation (Hewlett, 2004) for the WPC pastes blended with nanosilica and limestone are presented in Figures 8 and 9. It was found that the different NS+L combinations increased the amount of heat released, in other words, increased the velocity of dissolution.

It has already been reported that the nanosilica enhances the dissolution process of the cement and the precipitation of the hydration products (Gaitero et al., 2010), increasing the amount of heat released. But in the case of pastes with

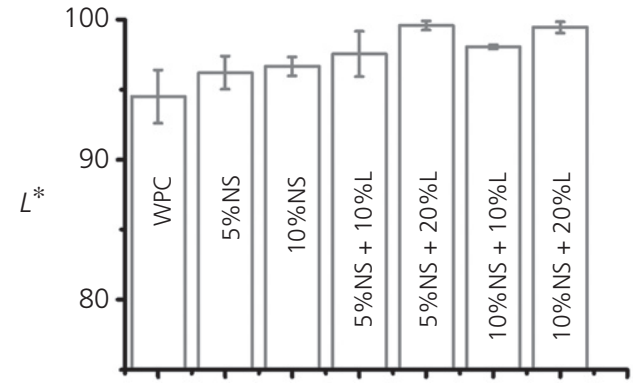

(a)

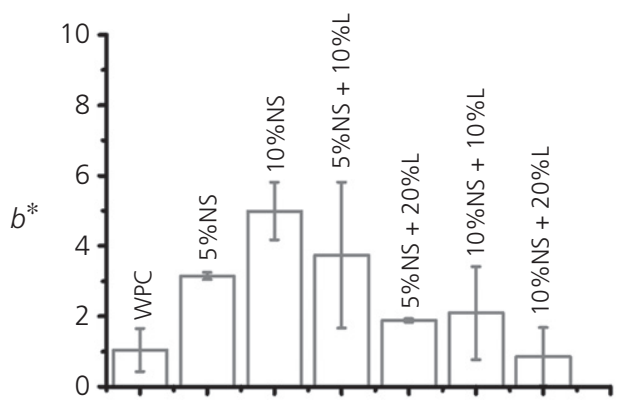

(c)

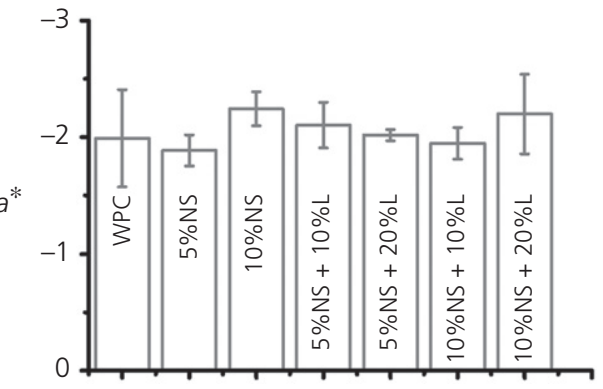

(b)

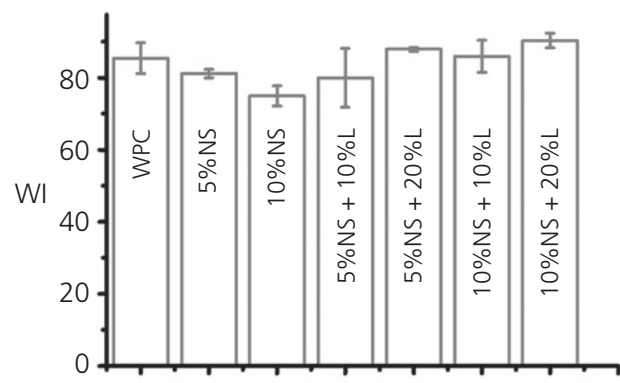

(d)

Figure 7. Colour coordinates $\left(L^{*}, a^{*}, b^{*}\right)$ and whiteness index (WI) of WPC pastes blended with nanosilica and limestone after $3 \mathrm{~d}$ of hydration 


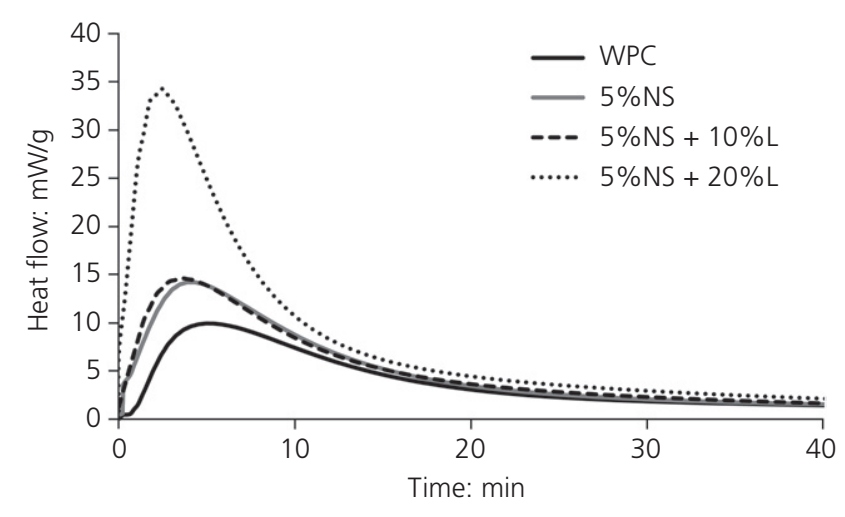

Figure 8. Normalised heat flow curves of WPC, $5 \%$ NS, $5 \% \mathrm{NS}+10 \% \mathrm{~L}$ and $5 \% \mathrm{NS}+20 \% \mathrm{~L}$ pastes, from 0 to $40 \mathrm{~min}$

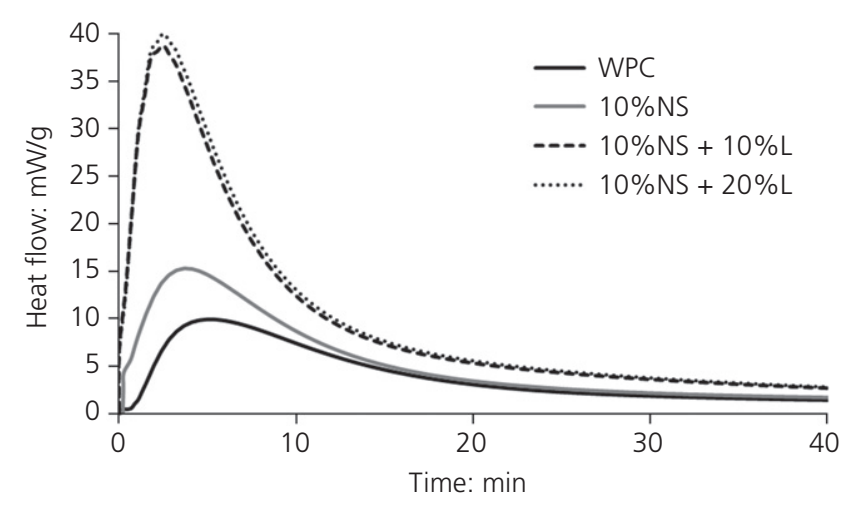

Figure 9. Normalised heat flow curves of WPC, $10 \% \mathrm{NS}$, $10 \% \mathrm{NS}+10 \% \mathrm{~L}$ and $10 \% \mathrm{NS}+20 \% \mathrm{~L}$ pastes, from 0 to $40 \mathrm{~min}$

limestone substitutions, the heat released should be lower owing to the dilution effect. However, it was found that for all the limestone substitutions, the heat release increased. This can be attributed to the variations in the water/WPC ratio caused by the limestone substitution. It can be seen in Table 2 that the samples blended with limestone have a higher water/WPC ratio; this means a lower amount of cement for the same amount of water when increasing the amount of limestone. This generates a more diluted system for the WPC, which requires a higher amount of $\mathrm{Ca}^{2+}$ to become saturated. This creates a more efficient dissolution scenario for WPC, enhancing the dissolution process of the anhydrous components of the cement (Rahhal et al., 2012). This process is further enhanced by the presence of nanosilica, which has a role providing nucleation points and accelerates the reaction (Hubler et al., 2011).

The results obtained for the second and third heat release peaks are presented in Figures 10 and 11: the first one associated with the $\mathrm{C}-\mathrm{S}-\mathrm{H}$ formation, the calcium hydroxie precipitation, and the second one with the AFt formation (Gaitero

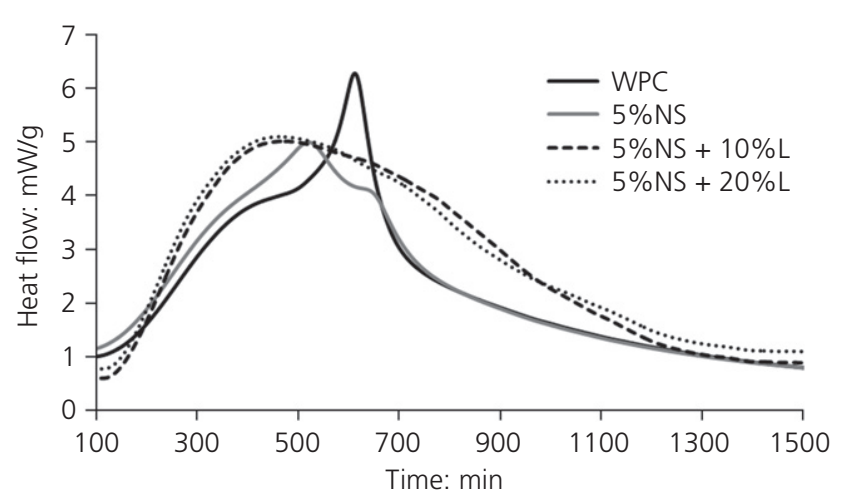

Figure 10. Normalised heat flow curves of WPC, $5 \%$ NS, $5 \% \mathrm{NS}+10 \% \mathrm{~L}$ and $5 \% \mathrm{NS}+20 \% \mathrm{~L}$ pastes, from 100 to $1500 \mathrm{~min}$

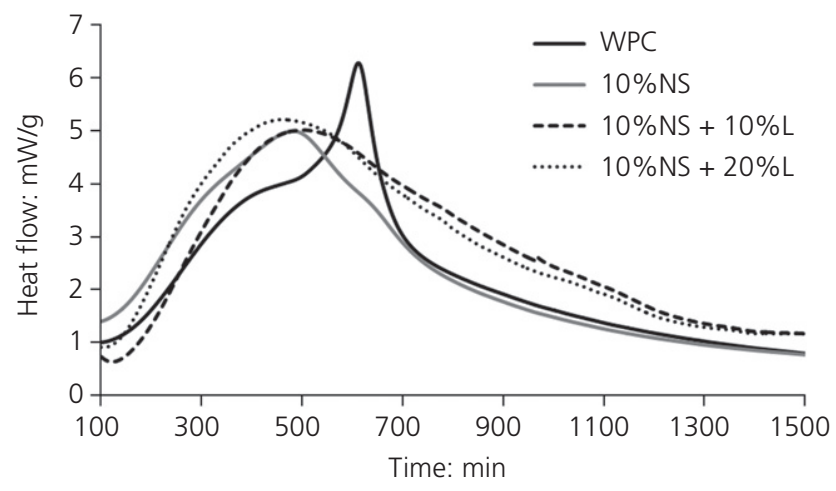

Figure 11. Normalised heat flow curves of WPC, $10 \%$ NS, $10 \% \mathrm{NS}+10 \% \mathrm{~L}$ and $10 \% \mathrm{NS}+20 \% \mathrm{~L}$ pastes, from 100 to $1500 \mathrm{~min}$

et al., 2010), for the WPC pastes blended with nanosilica and limestone. An acceleration of these processes by the combination of NS+L was identified in the samples, as the peaks were displaced to the left. It can be seen how the third peak, which is very well defined in the WPC sample, decreases drastically with the nanosilica addition. This indicates that the second AFt formation that took place in the WPC sample is much less important in the samples with nanosilica, because most of the AFt was formed during the first heat release peak.

\section{Results for compressive strength of}

\section{WPC/nanosilica/limestone mortars}

Compressive strength of WPC mortars blended with nanosilica and limestone using the same proportions detailed in Table 2 are presented in Figure 12. Mortars with 5\%NS showed approximately the same compressive strength as WPC mortars, whereas mortars with $10 \% \mathrm{NS}$ presented a higher strength than WPC mortars at all ages, attributable to the pozzolanic activity of nanosilica. For the mortars blended with limestone, it was found that during the first $3 \mathrm{~d}$ of hydration all samples except for $5 \% \mathrm{NS}+20 \% \mathrm{~L}$, which has the combination of the lowest 


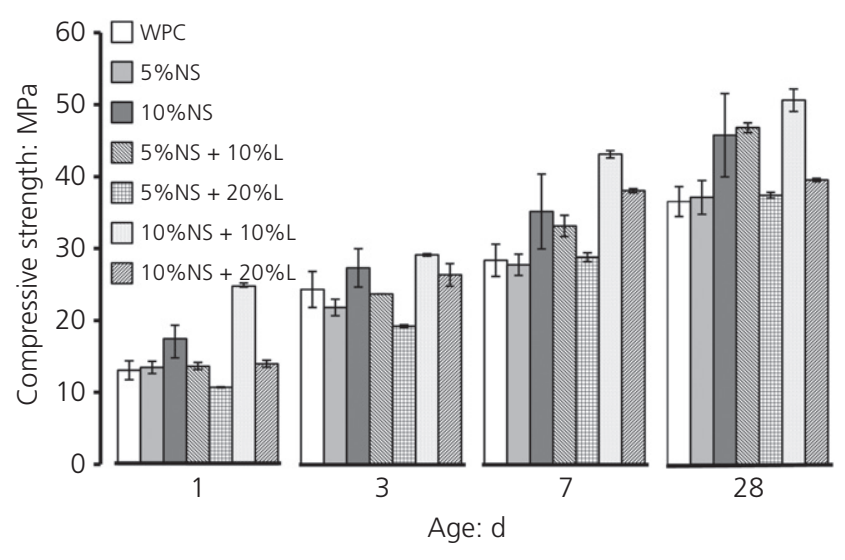

Figure 12. Compressive strength of WPC mortars blended with NS and $L$ after 1, 3, 7 and $28 d$ of curing

nanosilica and the highest limestone amounts, presented a strength at least equal to the plain WPC mortars; this means that the inclusion of nanosilica was able to compensate for the dilution effect of limestone. After 7 and $28 \mathrm{~d}$ of hydration, it was found that all samples reached at least the same strength as the plain WPC mortars. It should be noticed also that $5 \% \mathrm{NS}$ and $10 \% \mathrm{NS}$ generated a significant increase in strength after $28 \mathrm{~d}$ of hydration, and that the samples with $5 \% \mathrm{NS}+20 \% \mathrm{~L}$ and $10 \% \mathrm{NS}+20 \% \mathrm{~L}$ were able to maintain this strength gain.

The $10 \% \mathrm{NS}+10 \% \mathrm{~L}$ mortar, which has the combination of more nanosilica and less limestone, and presented the best mechanical performance within the limestone blended samples, also presented the highest amount of heat released in the first peak of the isothermal calorimetry curves, and the disappearance of the third heat release peak. This means that all the possible AFt was formed during the first hours of hydration, leaving a lower amount of $\mathrm{C}_{3} \mathrm{~A}$ available to form further $\mathrm{AFt}$ and to transform AFt into AFm. This phenomenon can be prompted by the nucleation effects of nanosilica (Tobón et al., 2012), or by the dilution of the liquid phase of the mixture from the limestone substitution (Rahhal et al., 2012). The experimental evidence available does not allow the separation of the individual effect from these two possible sources.

The TGA and XRD results showed that the improvement of strength of the mortars can be associated with an increase in the production of $\mathrm{C}-\mathrm{S}-\mathrm{H}$ from the reaction with calcium hydroxide due to the pozzolanic reaction of nanosilica, and to a higher formation of early-age AFt owing to the enhancement of the dissolution process of the anhydrous phases. Even though the substitution of cement by limestone decreased the total amount of hydration products present in the mortars owing to the dilution effect of the substitution, this dilution was not sufficiently significant to impact negatively on the development of compressive strength of the samples blended with the lowest amount of limestone.

\section{Final discussion}

The main findings can be described as follows. (a) The nanosilica increased and accelerated the formation of the hydrated phases (AFt, C-S-H, C-A-H, C-A-S-H and calcium hydroxide) during the hydration process, owing to the pozzolanic reaction and to the nucleation effect of the nanoparticles. (b) The substitution of cement by limestone decreased the amount of cement with respect to water, enhancing the dissolution process of the anhydrous components of the WPC. (c) The presence of AFt following the first day of hydration and the absence of gypsum indicate that, at the first stages of the hydration, all the gypsum reacted with the $\mathrm{C}_{3} \mathrm{~A}$ to form AFt. Substituting cement by limestone leaves a lower amount of $\mathrm{C}_{3} \mathrm{~A}$ available in the mixture; this implies that there is a lower potential to form AFm or secondary Aft at later ages.

With respect to the mechanical performance of the WPC mortars blended with nanosilica and limestone, it can be said that, at least after the first 28 hydration days, the substitution of WPC by limestone decreases the total amount of hydrates produced owing to dilution of the amount of cement present in the samples. However, nanosilica allows up to $20 \%$ of limestone to be used with no loss of compressive strength compared with the control mortar. The improvement found when the samples were blended with nanosilica plus limestone should not be explained only in terms of the total amount of hydrates produced, but also by a decrease in the porosity and densification of the matrix caused; both are known effects of nanosilica acting as pozzolan (Tobón et al., 2015), and limestone acting as filler (Colak, 2008).

Colorimetric studies showed that the effect of the substitution of cement by limestone generates an increase in the luminosity of the final product, with some deviations to the green and yellow, characteristic of the cement. Given these results, it can be said that nanosilica is an excellent option as a mineral addition for WPC, because it can improve the cement's properties in the fresh and hardened states without altering the whiteness of the product, which is fundamental for architectural applications. Also, replacing white cement by high-purity limestone increases the luminosity of the colour of the final product without altering its mechanical properties.

\section{Conclusions}

- Nanosilica is an excellent option as a mineral addition for WPC, because it can improve the cement's properties in the fresh and hardened states without altering the whiteness of the product, which is fundamental for architectural applications.

- High-purity limestone, although only an inert admixture, is an excellent material to combine with nanosilica within a WPC matrix because it increases the luminosity of the final product without affecting its mechanical properties. 


\section{Offprint provided courtesy of www.icevirtuallibrary.com Author copy for personal use, not for distribution}

- The improvement of strength of mortars can be associated with an increase in the production of $\mathrm{C}-\mathrm{S}-\mathrm{H}$ from the combination of calcium hydroxide owing to the pozzolanic reaction of nanosilica, and higher formation of early-age AFt due to the enhancement of the dissolution process of the anhydrous phases.

- The substitution of cement by limestone increases the luminosity of the paste, maintaining some deviations to the green and the yellow, characteristic of the WPC, and that are not influenced either by the nanosilica or by the limestone.

- Samples blended with nanosilica and limestone exhibit at least a similar strength to that of plain samples blended only with nanosilica and the plain WPC mortar, showing that for the evaluated percentages the nanosilica is capable of compensating for the lower amount of cement in the sample.

\section{REFERENCES}

Abd El Aleem S, Heikal M and Morsi WM (2014) Hydration characteristic, thermal expansion and microstructure of cement containing nano-silica. Construction and Building Materials 59: 151-160.

ASTM (2013) C778-13: Standard specification for standard sand. ASTM International, West Conshohocken, PA, USA.

ASTM (2014a) C348-14: Standard test method for flexural strength of hydraulic-cement mortars. ASTM International, West Conshohocken, PA, USA.

ASTM (2014b) C349-14: Standard test method for compressive strength of hydraulic-cement mortars (Using Portions of Prisms Broken in Flexure). ASTM International, West Conshohocken, PA, USA.

ASTM (2015a) C1437-15: Standard test method for flow of hydraulic cement mortar. ASTM International, West Conshohocken, PA, USA.

ASTM (2015b) E313-15e1: Standard practice for calculating yellowness and whiteness indices from instrumentally measured color coordinates. ASTM International, West Conshohocken, PA, USA.

ASTM (2016) C109/C109M-16a: Standard test method for compressive strength of hydraulic cement mortars (using 2-in. or [50-mm] cube specimens). ASTM International, West Conshohocken, PA, USA.

Badogiannis E, Kakali G, Dimopoulou G, Chaniotakis E and Tsivilis S (2005) Metakaolin as a main cement constituent: exploitation of poor Greek kaolins. Cement and Concrete Composites 27(2): 197-203.

Berra M, Carassiti F, Mangialardi T, Paolini AE and Sebastiani M (2012) Effects of nanosilica addition on workability and compressive strength of Portland cement pastes. Construction and Building Materials 35: 666-675.

Björnström J, Martinelly A, Matic A, Börjesson L and Panas I (2004) Accelerating effects of colloidal nano-silica for beneficial calcium-silicate-hydrate formation in cement. Chemical Physics Letters 392(1-3): 242-248.

Chen JJ, Thomas JJ, Taylor HFW and Jennings HM (2004) Solubility and structure of calcium silicate hydrate. Cement and Concrete Research 34(9): 1499-1519.

Colak A (2008) Effects of chrome oxide and limestone filler on the wear characteristics of paste and concretes made with white Portland cement. Construction and Building Materials 22(11): 2276-2280.

Courard L, Michel F and Pierard J (2011) Influence of clay in limestone fillers for self-compacting cement based composites. Construction and Building Materials 25(3): $1356-1361$.

Dellinghausen LM, Gastaldini ALG, Vanzin FJ and Veiga KK (2012) Total shrinkage, oxygen permeability, and chloride ion penetration in concrete made with white Portland cement and blast-furnace slag. Construction and Building Materials 37: 652-659.

Ferraro RM and Nanni A (2012) Effect of off-white rice husk ash on strength, porosity, conductivity and corrosion resistance of white concrete. Construction and Building Materials 31: 220-225.

Gaitero JJ, Campillo I, Mondal P and Shah S (2010) Small changes can make a great difference. Transportation Research Record: Journal of the Transportation Research Board 2141: 1-5.

Girão AV, Richardson IG, Taylor R and Brydson MD (2010) Composition, morphology and nanostructure of $\mathrm{C}-\mathrm{S}-\mathrm{H}$ in $70 \%$ white Portland cement-30\% fly ash blends hydrated at $55^{\circ} \mathrm{C}$. Cement and Concrete Research 40(9): 1350-1359.

Hamad BS (1995) Investigations of chemical and physical properties of white cement concrete. Advanced Cement Based Materials 2(4): 161-116.

Hewlett P (ed.) (2004) Lea's Chemistry of Cement and Concrete. Elsevier Science \& Technology Books, Oxford, UK.

Hubler M, Thomas J and Jennings $H$ (2011) Influence of nucleation seeding on the hydration kinetics and compressive strength of alkali activated slag paste. Cement and Concrete Research 41(8): 842-846.

Jal PK, Sudarshan M, Saha A, Patel S and Mishra BK (2004) Synthesis and characterization of nanosilica prepared by precipitation method. Colloids and Surfaces $A$ : Physicochemical and Engineering Aspects 240(1-3): 173-178.

Ji T (2005) Preliminary study on the water permeability and microstructure of concrete incorporating nano- $\mathrm{SiO}_{2}$. Cement and Concrete Research 35(10): 1943-1947.

Land G and Stephan D (2012) The influence of nano-silica on the hydration of ordinary Portland cement. Journal of Materials Science 47(2): 1011-1017.

Love CA, Richardson IG and Brough AR (2007) Composition and structure of $\mathrm{C}-\mathrm{S}-\mathrm{H}$ in white Portland cement-20\% metakaolin pastes hydrated at $25^{\circ} \mathrm{C}$. Cement and Concrete Research 37(2): 109-117.

Lübeck A, Gastaldini ALG, Barin DS and Siqueira HC (2012) Compressive strength and electrical properties of concrete 
with white Portland cement and blast-furnace slag. Cement and Concrete Composites 34(3): 392-399.

Mendoza O and Tobón JI (2013) An alternative thermal method for identification of pozzolanic activity in $\mathrm{Ca}(\mathrm{OH})_{2} /$ pozzolan pastes. Journal of Thermal Analysis and Calorimetry 114(2): 589-596.

Mendoza O, Sierra G and Tobón J (2014) Effect of the reagglomeration process of multi-walled carbon nanotubes dispersions on the early activity of nanosilica in cement composites. Construction and Building Materials 54: 550-557.

Palm S, Proske T, Rezvani M et al. (2016) Cements with a high limestone content - mechanical properties, durability and ecological characteristics of the concrete. Construction and Building Materials 119: 308-318.

Pisello Al (2015) High-albedo roof coatings for reducing building cooling needs. In Eco-Efficient Materials for Mitigating Building Cooling Needs (Pacheco-Torgal F, Labrincha JA, Cabeza LF and Granqvist CG (eds)). Woodhead Publishing, Oxford, UK, pp. 243-268.

Rahhal V, Bonavetti V, Trusilewicz L, Pedrajas C and Talero R (2012) Role of the filler on Portland cement hydration at early ages. Construction and Building Materials 27(1): 82-90.

Ramachandran VS, Paroli RM, Beaudoin JJ and Delgado AH (2002) Handbook of Thermal Analysis of Construction Materials. Noyes Publications, Norwich, NY, USA.
Sáez del Bosque I, Martínez-Ramírez S and Blanco-Varela M (2013) Combined effect of amorphous nanosilica and temperature on white Portland cement hydration. Industrial and Engineering Chemistry Research 52(34): 11866-11874.

Siddique R and Klaus J (2009) Influence of metakaolin on the properties of mortar and concrete: a review. Applied Clay Science 43(3-4): 392-400.

Talero R (2005) Performance of metakaolin and Portland cements in ettringite formation as determined by ASTM C 452-68: kinetic and morphological differences. Cement and Concrete Research 35(7): 1269-1284.

Tobón Jl, Payá JJ, Borrachero MV and Restrepo OJ (2012) Mineralogical evolution of Portland cement blended with silica nanoparticles and its effect on mechanical strength. Construction and Building Materials 36: 736-742.

Tobón JI, Payá J and Restrepo OJ (2015) Study of durability of Portland cement mortars blended with silica nanoparticles. Construction and Building Materials 80: 92-97.

Veiga KK and Gastaldini ALG (2012) Sulfate attack on a white Portland cement with activated slag. Construction and Building Materials 34: 494-503.

Zaeni A, Bandyopadhyay S, Yu A et al. (2010) Colour control in fly ash as a combined function of particle size and chemical composition. Fuel 89(2): 399-404.

\section{HOW CAN YOU CONTRIBUTE?}

To discuss this paper, please submit up to 500 words to the editor at journals@ice.org.uk. Your contribution will be forwarded to the author(s) for a reply and, if considered appropriate by the editorial board, it will be published as a discussion in a future issue of the journal. 